\title{
Growth Profile of 100 Breastfeeding Children with Early Introduction of Infant Formulas in Abidjan, Côte d'Ivoire
}

\author{
Richard Azagoh-Kouadio ${ }^{*}$, Kouadio Vincent Asse ${ }^{2}$, Jean-Jacques Yao Atteby', Lassina Cisse ${ }^{1}$, \\ Jacob Slanziahuelie Enoh'1, Ehouman Mocket Adolphe ${ }^{3}$, Stéphane Koffi-Djadan', \\ Soumahoro Oulai ${ }^{1}$ \\ ${ }^{1}$ Paediatric Ward of University and Teaching Hospital of Treichville, Abidjan, Côte d'Ivoire \\ ${ }^{2}$ Paediatric Ward of University and Teaching Hospital of Bouake, Bouaké, Côte d'Ivoire \\ ${ }^{3}$ University of Stellenbosch, Cape Town, South Africa \\ Email: ^azagoh.richard@gmail.com, assevinc2014@gmail.com, attebyjj@yahoo.fr, cisselassi@hotmail.fr, jacobeno2006@yahoo.fr, \\ olopam2@gmail.com,djadansteph@yahoo.fr, oulsoum@yahoo.fr
}

How to cite this paper: Azagoh-Kouadio, R., Asse, K.V., Yao Atteby, J.-J., Cisse, L., Enoh, J.S., Adolphe, E.M., Koffi-Djadan, S. and Oulail, S. (2017) Growth Profile of 100 Breastfeeding Children with Early Introduction of Infant Formulas in Abidjan, Côte d'Ivoire. Open Journal of Pediatrics, 7, 236-244. https://doi.org/10.4236/ojped.2017.74027

Received: September 16, 2017 Accepted: November 18, 2017 Published: November 21, 2017

Copyright $\odot 2017$ by authors and Scientific Research Publishing Inc. This work is licensed under the Creative Commons Attribution International License (CC BY 4.0).

http://creativecommons.org/licenses/by/4.0/

\begin{abstract}
Objective: To describe the growth profile of breastfeeding babies following early introduction of infant formulas to improve the feeding pattern of the young infant. Methodology: This is a longitudinal descriptive study conducted in 2 medical clinics in Abidjan from 11-Jun-2013 to 15-Dec-2016 on 100 healthy newborn babies with the introduction of infant formulas before 6 months of life. The anthropometrics parameters were compared to those of WHO. Results: The exclusive breastfeeding rate was $5 \%$. Ablactation occurred within 12 months in $95 \%$ of cases. All Infants have doubled and tripled their birth weight at 3 and 9 months respectively. The height and the head circumference at birth increased by $50 \%$ and $37 \%$ respectively at 12 months. Compared to WHO growth charts, the weight gain for the girls at 3 months was $12.4 \%$ higher and for the boys was $7.3 \%$ higher at 6 months. On the other hands, the statural gain at 12 months was $50 \%$ lower than the WHO standards while the head circumference was $37.8 \%$ and $45.5 \%$ higher than the WHO standards in boys and girls respectively. At 3 months, the prevalence of stunting was $26.1 \%$ for boys and $13.3 \%$ for girls. Lastly, at 12 months, the BMI showed $10 \%$ overweight and $19 \%$ obesity. Conclusion: Breastfeeding associated with an early introduction of infant formulas increases the risk of malnutrition of the young infant. We advise to avoid it and recommend an exclusive breastfeeding.
\end{abstract}

\section{Keywords}

Infant, Exclusive Breastfeeding, Infant Formulas, Growth, WHO Standards, 


\section{Introduction}

During the first 1000 days of life, uncontrolled feeding of the newborn increases the child's risk of malnutrition which will later enhance the possibility of metabolic diseases such as obesity, diabetes and high blood pressure in adulthood [1].

Thus, WHO recommends exclusive breastfeeding for up to 6 months, food diversification from 6 months, family meal in addition to the breastfeeding between 12 - 24 months, and final weaning at 24 months [2].

These recommendations have been adopted by the Republic of Côte d'Ivoire since the year 2000 and it is promoted via the National Nutrition Program. This program regularly refreshes the knowledge of health care providers and raises public awareness of the recommendations for a better nutrition of young infants to reduce the current malnutrition rate of $28 \%$ for chronic malnutrition, of which almost half (12\%) are in the form of severe acute malnutrition [3]. But in practice, we find that in urban areas, many pediatricians deviate from the recommendations and combine to the breast milk a substitute of maternal milk before 6 months. Are the growth patterns of these children comparable to the WHO reference population?

In other words, do these children have a greater risk of malnutrition? The objective of the study was to describe the growth profile of these children as compared to WHO growth standards to improve the feeding behavior of these infants.

\section{Patients and Methods}

\subsection{Patients}

This is a longitudinal descriptive study that took place in two private medical clinics in the city of Abidjan. It covers the period from 11 June 2013 to 15 December 2016.

These two dates correspond respectively to the date of birth of the study first newborn and to the study $100^{\text {th }}$ newborn 12 months in the study. The choice of the two clinics was made due to preventive consultation provided by pediatricians and trained health personnel in quality requirements and willing to undergo a quality control test.

The study population is made up of newborn; outpatients in these two medical clinics were included in the study, all eutrophic, healthy newborns at term with breastfeeding and breast milk, with the introduction of infant formulas before 6 months of life. They have been monitored monthly over a period of at least 12 months, taking into account the following indicators: weight, height and head circumference. Not included in the study:

1) All eutrophic, malformed newborns at term with a digestive organic pathology. 
2) All eutrophic, newborns at term hospitalized in the neonatal period.

3) All eutrophic, healthy newborns at term that the parent did not consent to take part in the study.

\subsection{Methods}

The children included in the study benefited from a monthly preventive consultation with assessment of diet, growth and psychomotor development. The feeding of the infant was conducted by the parents in accordance with the advice provided by the pediatrician.

The appreciation of quantitative growth was done outside the meal, at rest on a calm and non-agitated child. The measures were first taken by the caregiver then checked by the pediatrician. When there was a discrepancy between the two measures, the pediatrician performed a third measure.

The measuring equipment used in both medical centers was identical and calibrated in the same way. The weight was measured with an ADE model 116,800 baby scale (Gmbh \& Co., Germany) in mechanical cuvette, graduation in kilogram with a maximum load of $15 \mathrm{~kg}$.

The height was measured with a horizontal measuring rod graduated from 0 $120 \mathrm{~cm}$ and the head circumference by a measuring-tape $(0-150 \mathrm{~cm})$. The weighing was carried out on a naked infant. The infant was measured without his shoes, wearing a light undergarment or his diaper. He was lying on his back in the center of the board, flat on the surface.

His eyes looked at the ceiling and both legs extended. The toes pointed upward and the feet laying flat. The Length was measured to the nearest $0.1 \mathrm{~cm}$. To measure the head circumference, the examiner placed the graduated tape just above the eyebrows, over the ears and over the bulging part at the back of the head.

The tape measure used was flexible and non-stretchable. The head circumference was measured to the nearest $0.1 \mathrm{~cm}$. Body mass index (BMI) was determined by the following formula: weight $(\mathrm{kg}) /$ height $^{2}\left(\mathrm{~m}^{2}\right)$. Stunting was defined as a BMI less than the $3^{\text {rd }}$ percentile, overweight by a BMI greater than $97^{\text {th }}$ percentile, and obesity by a BMI greater than $99.9^{\text {th }}$ percentile (Table 1) [4].

At the end of the consultation, the information collected by the pediatrician

Table 1. Summary of interpretations of the different WHO growth charts [4].

\begin{tabular}{ccc}
\hline State of Growth & Indicator & Percentile \\
\hline Underweight & Weight-for-age & $<3$ ème \\
Stunted & Height/Length-for-age & $<3$ ème \\
Wasted & Weight-for-length & $<3$ ème \\
Risk of overweight & Weight-for-length & $>85$ ème \\
Overweight & Weight-for-length & $>97$ ème \\
Obese & Weight-for-length & $>99.9$ ème \\
\hline
\end{tabular}


was recorded in the consultation register and in the mother-to-child health booklet. These documents were used to fill out the survey card containing the study variables: prevalence of exclusive breastfeeding, weight, height, head circumference, BMI.

The authorization from the scientific medical board of the two medical centers was obtained before the study was carried out. Furthermore, all parents of the children included have given their verbal consent. The data collected was analyzed using the EPI DATA Analysis V2.2.2.182 software.

The analysis consisted of determining the frequencies, calculating the averages with standard deviations and comparing the proportions.

\section{Results}

\section{1) Total population}

Fifty-five girls and forty-five boys were included in the study. The breastmilk substitute was introduced before 3 months in $95 \%$ of cases.

At 3 months, all mothers had introduced the breastmilk substitute. The reasons for the introduction of the breastmilk substitute were to resume work (65\%), breast milk deficiency (24\%) and aesthetics (11\%).

The exclusive breastfeeding rate was $5 \%$ before 3 months. Ablactation occurred before 12 months in $95 \%$ of cases. $8 \%$ of the mother had a primary level of education, $49 \%$ secondary level and $43 \%$ tertiary level of education. Furthermore, $53 \%$ of them had an activity with a fixed monthly income, $36 \%$ variable while $11 \%$ had no occupation.

All study infants have doubled and tripled their birth weight at 3 months and 9 months respectively. The length and the head circumference at birth increased by $50 \%$ and $37 \%$ respectively at 12 months.

\section{2) Growth profile of boys}

The quantitative growth profile of the 45 boys from birth to 12 months is shown in Figure 1. Figure 2 illustrates the growth profile of the 45 boys compared to the WHO reference standards.

\section{3) Growth profile of girls}

The quantitative growth profile of the 55 girls from birth to 12 months is shown in Figure 3. Figure 4 illustrates the growth profile of the 55 girls compared to the WHO reference standards.

\section{Discussion}

These results should be considered with care because the sample size is small and the children included come only from private medical facilities. The data on the feeding of these children come from the parents' declaration and notified in the consultation register or in the mother and child health booklet by the consultant pediatricians.

A memory bias or transcription error of the data cannot be ruled out. Despite the limitations of the study, the following discussion points emerged. 
The objective of this work is to describe the growth profile of 100 breast-fed infants with an introduction of an infant formula before the age of six months and followed in preventive consultation for 12 months in two private medical clinics in Abidjan. The study found that the rate of exclusive breastfeeding was very low, $5 \%$ of cases.

Before the age of three months, the growth profile of the children, regardless

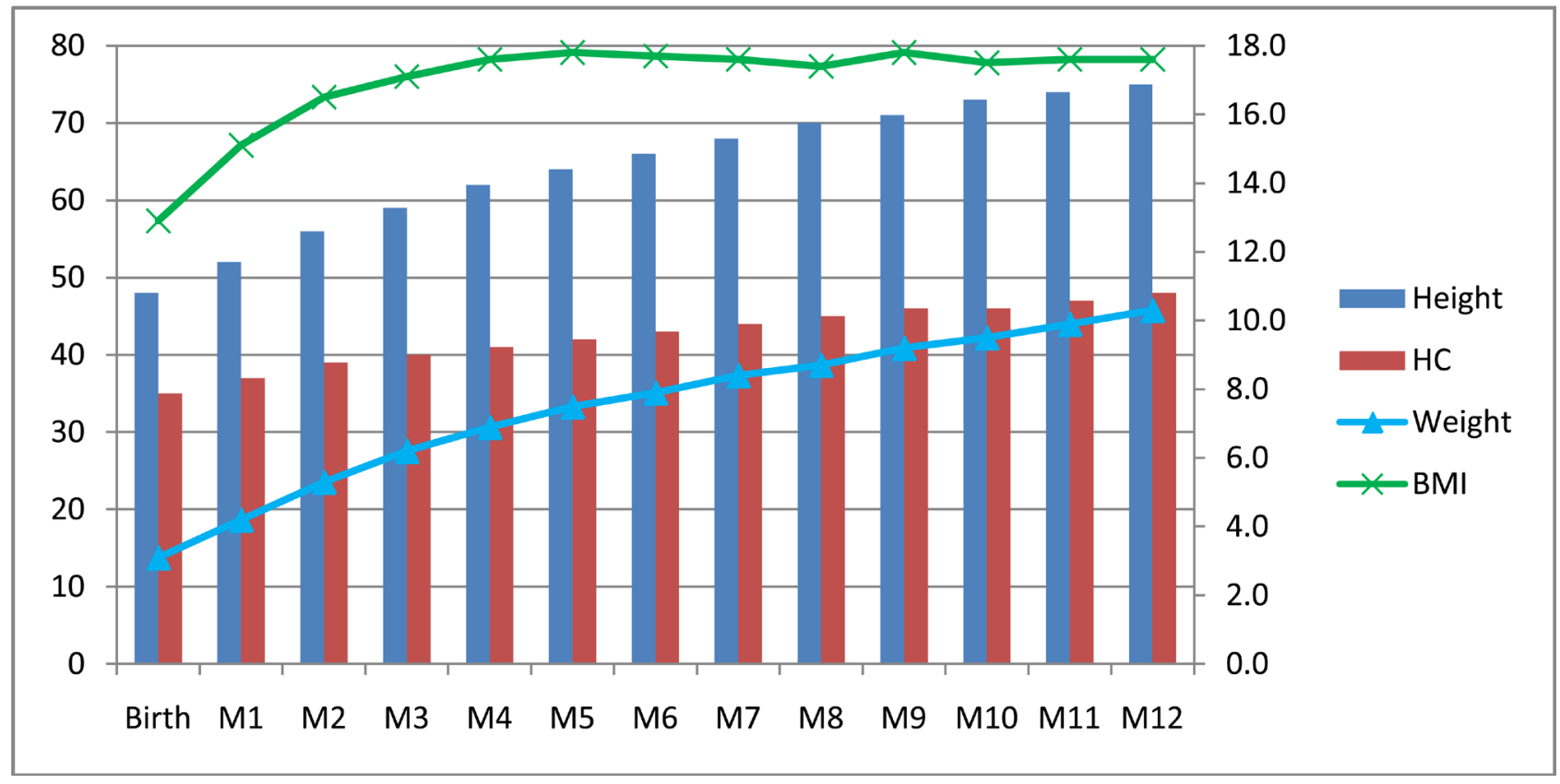

Figure 1. Chart combining the height, the HC, the weight and the BMI in boys.

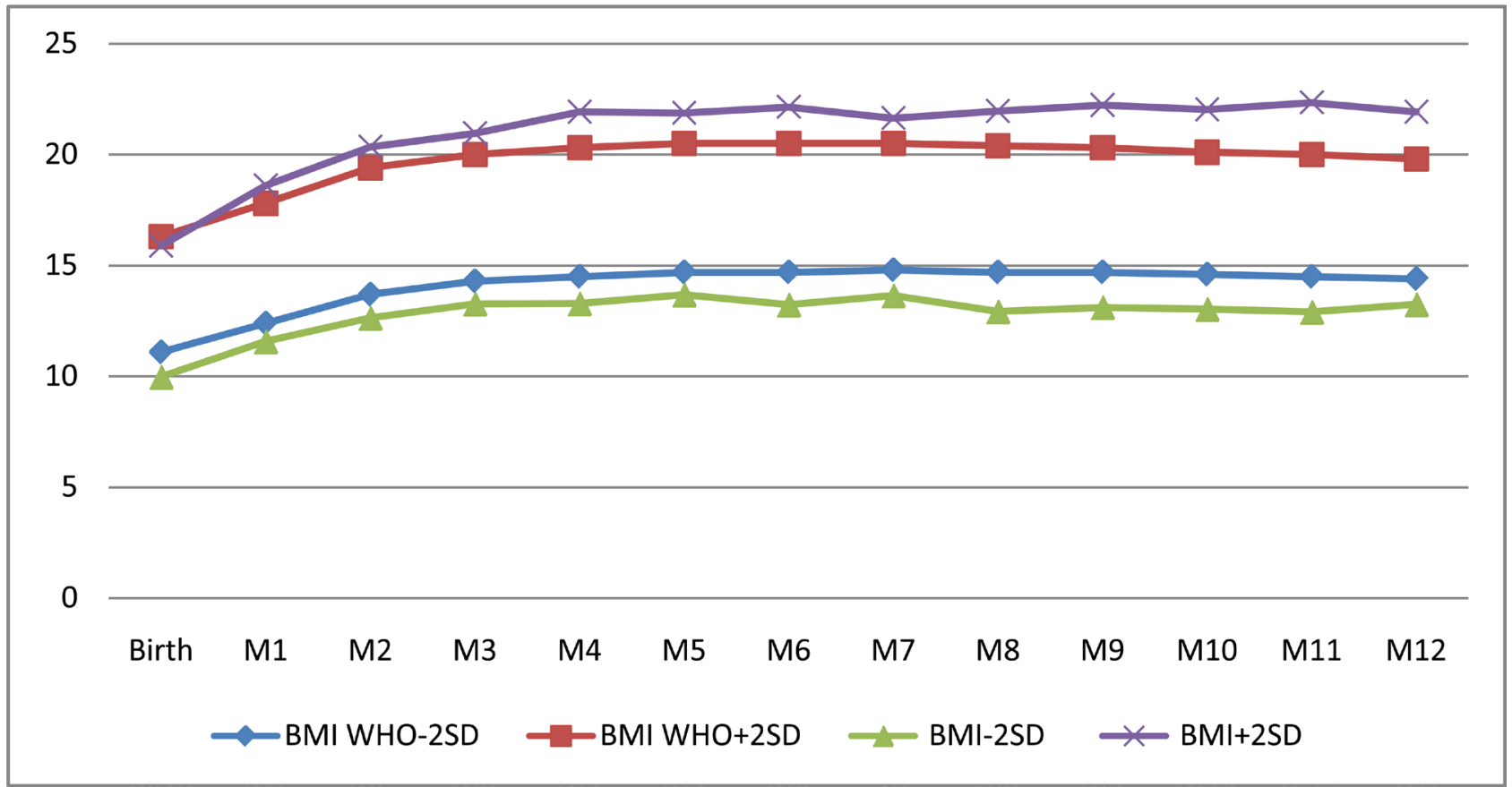

Figure 2. Comparison of the BMI of the $97^{\text {th }}$ percentile and the $3^{\text {rd }}$ percentile of the boys from 0 to 12 months with WHO growth charts. 


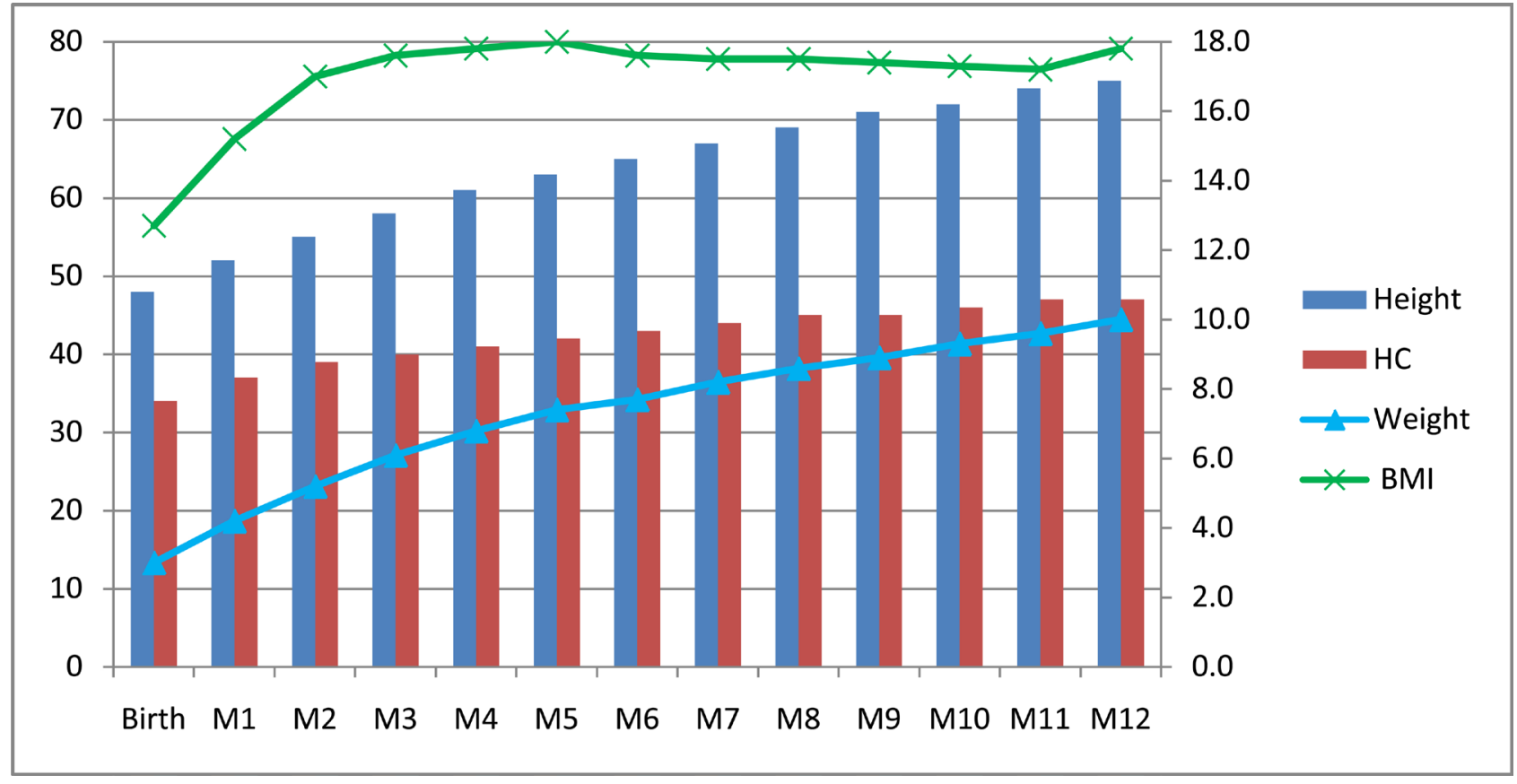

Figure 3. Chart combining the height, the HC, the weight and the BMI in girls.

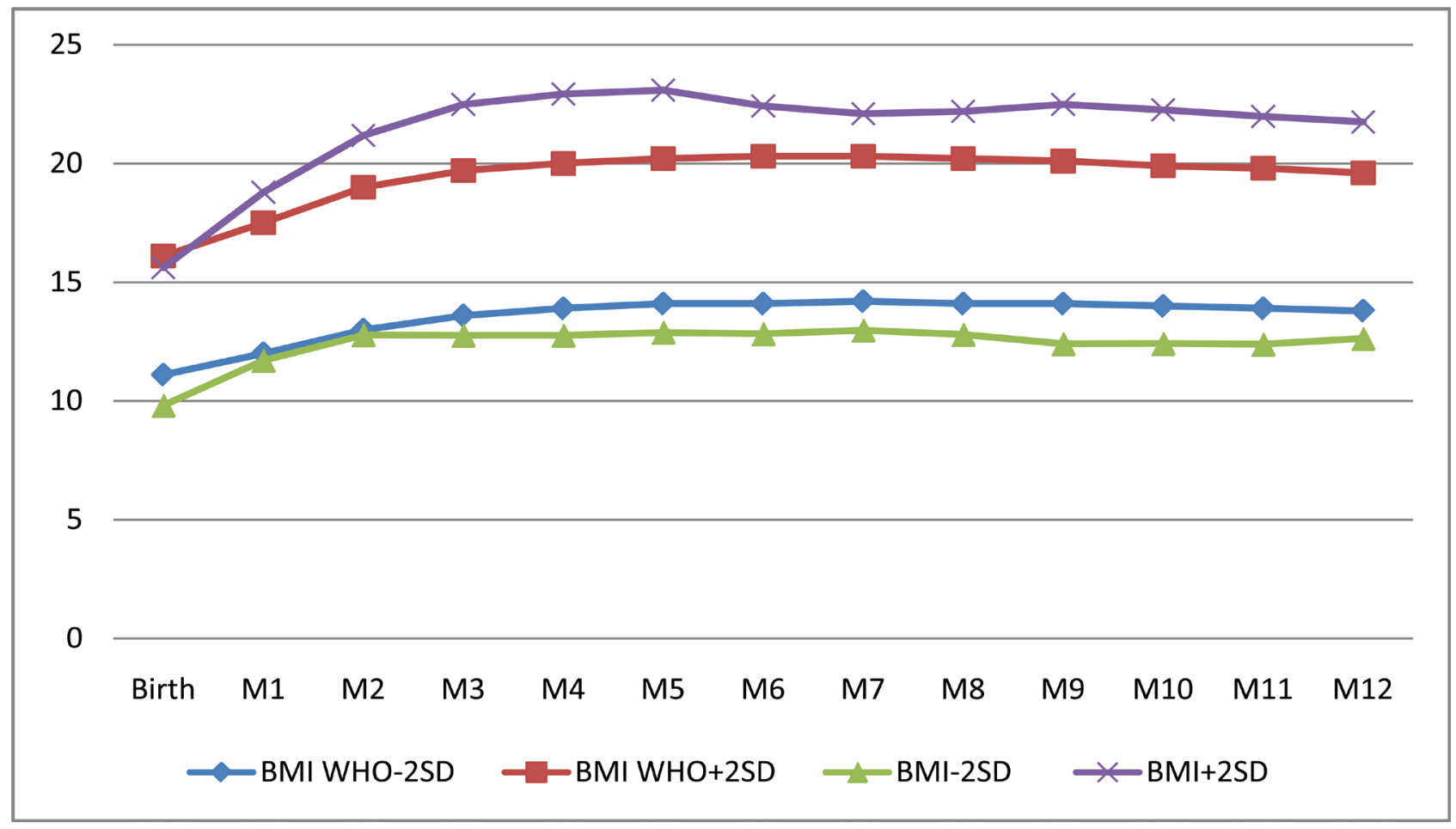

Figure 4. Comparison of the BMI of the $97^{\text {th }}$ percentile and the $3^{\text {rd }}$ percentile of the girls from 0 to 12 months with WHO growth charts.

of gender, is almost superimposed on that of WHO. From the age of 6 months to 12 months the growth profile becomes different. Study children were bigger at the $97^{\text {th }}$ percentile but smaller at the $3^{\text {rd }}$ percentile. They have a tendency to obesity. 
When the anthropometric constants are considered, the study reveals at 6 months that the weight and height are below the normal while the head circumference is kept within normal limits.

At 12 months of age, a comparison of the study infants growth profile with the WHO growth standards revealed $11 \%$ overweight, $16 \%$ obese, $100 \%$ stunted growth in the boys and $9 \%$ overweight, $22 \%$ obese and $100 \%$ stunted growth in girls.

Regarding the prevalence of exclusive breastfeeding, the study revealed $5 \%$. This rate is very low compared to the national average of $12 \%$ [3].

The main reason given for the early introduction of the breastmilk substitutes at 3 months is the return to work (65\%). Indeed, the study reveals that $53 \%$ of nursing mothers carry out a fixed-wage activity (employed). The legal duration of maternity leave in Côte d'Ivoire is fourteen consecutive weeks, with eight weeks (2 months) later for delivery [5].

The return to work should not constitute an obstacle to the conduct of breastfeeding since the breastfeeding woman can extract her milk (breast pump) and give it to the infant during the hours of absence. But the extraction of breast milk is challenged by some breastfeeding women for aesthetic reasons, $11 \%$ of the cases in the study, because it would favor the flattening of the breasts.

At the work place, about a quarter of the mothers introducing the breast milk substitute early evoke breast milk deficiency as a reason. Hypo-galactorrhea of congenital origin is rare to see and is exceptional cases [6].

In most cases, it is caused by a poor positioning of the child to the breasts [7] [8].

Other reasons have been mentioned by Moyen et al. [9] in Brazzaville to explain the decline of exclusive breastfeeding. According to these authors it is the ignorance and pejorative ideas of mothers educated about breastfeeding.

Mothers with a higher level of education tend to adopt modern psychosocial and societal ideas which lead them to abandon breastfeeding as an ancient nutritional practice [9].

In developed countries, mothers with a higher level of education were more supportive of breastfeeding [10]. Sensitization of breastfeeding women targeting the three reasons mentioned could increase the rate of exclusive breastfeeding reported in the study.

Before 3 months, the growth profile of the children, whatever the sex is harmonious and almost superimposable to that of the WHO standards. This is because the two populations of children are fed mainly with breast milk. But at 6 months the weight and height of the children of the study become lower than the normal while the head circumference remained within the limits of the normal.

In the first six months of life, the population of children responsible for WHO growth standards was exclusively breastfed [11], while the children in the study received in addition substitutes of breast milk. Breast milk contains all macronutrients, micronutrients, water, antibodies, and specific growth factors in sufficient quality and quantity that guarantee the harmonious growth of young infants 
up to 6 months [12].

When the nutrition is inadequate during the first 6 months of life, the brain growth is preserved and maintained at the expense of the weight and height. Asse and collaborators [13] reported in 2014 a similar result in France. Between 6 and 12 months, the growth profile of the study children becomes very different. They are bigger at the $97^{\text {th }}$ percentile but smaller at the $3^{\text {rd }}$ percentile.

The BMI at 12 month, shows $11.11 \%$ overweight, $15.55 \%$ obese, $11.1 \%$ stunted growth in the boys and $9.1 \%$ overweight, $21.8 \%$ obese and $3.6 \%$ stunted growth in girls. The children fed with infant milk with high protein contents have a significantly body weight and body mass index than those who are breastfed [14].

Oddy W.H. et al. reported that the use of infant formulas other than breast milk before the $6^{\text {th }}$ month is a risk factor for overweight or obesity [15]. Some infant formulas associated with breasts in our study might have a high protein contents. The high protein content induces the production of insulin-forming amino acids.

This promotes the secretion of insulin-like Growth Factor (IGF1), a growth factor that causes overweight and obesity [16]. In essence, this confirms once again that exclusive breastfeeding should be the mode of nutrition to be favored during the first 6 months of life. Early introduction of infant formulas in addition to breast prior to 6 months promotes immediate malnutrition in young infants and increases the risk of metabolic syndrome in adulthood [1].

\section{Conclusions}

The growth profile of breastfed infants with early introduction of infant formulas before six months compared to that of WHO standards shows a tendency towards overweight and obesity. This mode of nutrition should be avoided by pediatricians providing preventive consultations.

We recommend exclusive breastfeeding for up to 6 months in accordance with the guidelines of the National Nutrition Program in Côte d'Ivoire, given the beneficial effects of breastfeeding in the short and long term.

\section{Acknowledgements}

We thank the management and all the staff of the two clinics involved in the study.

\section{Contribution of the Authors}

All authors have contributed intellectually to the drafting and revision of this manuscript.

\section{References}

[1] Brands, B., Demmelmair, H. and Koletzko, B. (2014) How Growth Due to Infant Nutrition Influences Obesity and Later Disease Risk. Acta Paediatrica, 103, 578-585. https://doi.org/10.1111/apa.12593

[2] WHO and UNICEF (1993) WHO/CDR/93.4, UNICEF/NUT93.2, Conseil en allaitement, Cours de formation, Manuel de participant. [Breastfeeding Council: Training 
Courses; Participant's Manual.] 186 p.

http://apps.who.int/iris/bitstream/10665/63487/3/WHO_CDR_93.5_fre.pdf

[3] Demographic and Health Survey and Multiple Indicators EDSCI-III (2013) Summary Report Côte d'Ivoire 2011-2012 by Ministry of Health and the Fight against HIV/AIDS \& National Institute of Statistics (INS).

[4] Alberta Health Services (2011) Evaluation et counseling relatifs aux normes de croissance de l'OMS. [Growth Assessment and Counselling Summary Sheet.] Messages clés et actions. https://www.whogrowthcharts.ca

[5] Ivory Coast National Laws on Labour, Social Security and Related Human Rights (1995) Act No. 95/15 of 12 Jan 1995 Patterning to the Labor Code. Chapter 3, Work of Women and Children 23.1-23.9. Official Newspaper, No. 8, 153-177.

[6] Gatti, L. (2008) Maternal Perceptions of Insufficient Milk Supply in Breastfeeding. Journal of Nursing Scholarship, 40, 355-363. https://doi.org/10.1111/j.1547-5069.2008.00234.x

[7] Gremmo-Feger, G. (2008) Comprendre la physiologie de la lactation pour un accompagnement optimal de l'allaitement. [Understand the Physiology of Lactation for Optimal Support of Breastfeeding.] https://pro.perinatalite.org/fichs/14051.pdf

[8] Geddes, D.T., Kent, J.C., Mitoulas, L.R. and Hartmann, P.E. (2008) Tongue Movement and Intra-Oral Vacuum in Breastfeeding Infants. Early Human Development, 84, 471-477 https://doi.org/10.1016/j.earlhumdev.2007.12.008

[9] Moyen, E., Moigny Gaju, Y., Kambourou, J., Ocko, A.P., Ekouya Bowassa, G., Ganza-Zandzou, P.S., Atanda, H.L. and Moyen, G. (2015) Conduite de la diversification alimentaire chez le nourrisson à Brazzaville. [Conducting Dietary Diversification in Infants in Brazzaville.] Médecine d'Afrique Noire, 62, 191-199.

[10] Kassam-Lallanie, D., Moynagh, K., Ross, H., Sellar, L. and Sigmundson, C. (2002) Infant Feeding in Halton. Halton Regional Health Department, Ontario, Canada.

[11] Ziegler, E.E. and Nelson, S.E. (2007) Les nouvelles normes de croissance de l'OMS Comparaison à d'autres courbes de croissance. [WHO's New Growth Standards, Comparison to Other Growth Charts.] Annales Nestlé, 65, 111-117. https://doi.org/10.1159/000141032

[12] Rieu, D. (2002) Allaitement maternel et nutrition du nouveau-né et du nourrisson. [Breastfeeding and Nutrition of Newborns and Infants.] Archives de Pédiatrie, 9, 121-122. https://doi.org/10.1016/S0929-693X(01)00900-9

[13] Asse, K.V., Pejoan, H., Chebbi, Y. and Gatel, P. (2014) Évaluation de la prise en charge nutritionnelle du nouveau-né au Centre hospitalier Courbevoie-Neuilly-Puteaux (France). [Assessment of Newborn Nutritional Management at the Courbevoie-Neuilly-surSeine-Puteaux Hospital) (France).] Journal de pédiatrie et de puériculture, 27, 154-163. https://doi.org/10.1016/j.jpp.2014.04.006

[14] Armstrong, J. and Reilly, J.J. (2002) Child Health Information Team. Breastfeeding and Lowering the Risk of Childhood Obesity. Lancet, 359, 2003-2004. https://doi.org/10.1016/S0140-6736(02)08837-2

[15] Oddy, W.H., Mori, T.A., Huang, R.C., Marsh, J.A., Pennell, C.E., Chivers, P.T., Hands, B.P., Jacoby, P., Rzehak, P., Koletzko, B.V. and Beilin, L.J. (2014) Early Infant Feeding and Adiposity Risk: From Infancy to Adulthood. Annals of Nutrition and Metabolism, 64, 262-270. https://doi.org/10.1159/000365031

[16] Grunewald, M., Hellmuth, C., Demmelmair, H. and Koletzko, B. (2014) Excessive Weight Gain during Full Breast Feeding. Annals of Nutrition and Metabolism, 64, 271-275. https://doi.org/10.1159/000365033 